\title{
A relevância do dividendo adicional proposto
}

\section{The value-relevance of additional proposed dividend}

La relevancia de dividendo adicional propuesto

\section{Ricardo Luiz Menezes da Silva}

Doutor em Ciências Contábeis pela Universidade de São Paulo

Professor no Departamento de Contabilidade da Faculdade de Economia, Administração e Contabilidade de Ribeirão Preto - Universidade de São Paulo

Endereço: Av. Bandeirantes, n॰ 3900, Vila Monte Alegre

CEP: 14.040-905 - Ribeirão Preto/SP - Brasil

Email: rlms@fearp.usp.br

Telefone: +55 (16) 3315-9016

\section{Paula Carolina Ciampaglia Nardi}

Doutora em Administração de Organizações

Professora no Departamento de Contabilidade da Faculdade de Economia, Administração e Contabilidade de Ribeirão Preto - Universidade de São Paulo

Endereço: Av. Bandeirantes, no 3900, Vila Monte Alegre

CEP: 14.040-905 - Ribeirão Preto/SP - Brasil

Email: paulanardi@fearp.usp.br

Telefone: +55 (16) 3315-9022

\section{Rafaella Tonani}

Mestranda em Controladoria e Contabilidade pela Faculdade de Economia, Administração e Contabilidade de Ribeirão Preto - Universidade de São Paulo

Endereço: Av. Bandeirantes, n॰ 3900, Vila Monte Alegre

CEP: 14.040-905 - Ribeirão Preto/SP - Brasil

Email: rafaellatonani@gmail.com

Telefone: +55 (16) 3315-4746

Artigo recebido em 09/06/2015. Revisado por pares em 07/06/2016. Reformulado em 07/08/2016. Recomendado para publicação em 12/08/2016 por Sandra Rolim Ensslin (Editora Científica). Publicado em 26/08/2016. 


\title{
Resumo
}

Com base na Teoria da Sinalização dos Dividendos, estes são vistos como sinalizadores de informação ao mercado. Contudo, após adoção das IFRS, muitas empresas passaram a fazer uso do Dividendo Adicional Proposto (DAP), que, até à deliberação dos sócios, não se caracteriza como uma obrigação. Nesse contexto, o objetivo do estudo foi analisar a relevância da divulgação do DAP para o mercado de capitais brasileiro. Por meio de regressões com dados em painel, entre 2010 e 2012, verificou-se que o DAP influencia o preço das ações devido ao seu conteúdo informacional, revelando informação útil para o mercado, coerente com estudos da área. Assim, como contribuição, o estudo evidencia que, na visão dos investidores, o aumento na distribuição dos dividendos indica um sinal positivo de maiores lucros no futuro, coerente com a Teoria da Sinalização dos Dividendos, mesmo que esses dividendos ainda não sejam uma obrigação na data de apresentação do balanço.

Palavras-chave: Dividendo adicional proposto. ICPC 08. Value relevance.

\begin{abstract}
Based on the Theory of Dividends Signaling, they are seen as market information flags. However, after adoption of IFRS many companies now make use of the Additional Dividend Proposed (DAP), which, until the resolution of the shareholders, not characterized as an obligation. In this context, the objective of the study was to analyze the relevance of the dissemination of DAP for the Brazilian capital market. Through regressions with panel data, between 2010-2012, it was found that the DAP influence the stock price due to its informational content, revealing useful information to the market, consistent with area studies. Thus, as a contribution, the study shows that investors' view, the increase in the distribution of dividends indicates a positive sign of greater profits in the future, consistent with the Theory of Dividends Signaling, even if these dividends not be an obligation on date of balance sheet presentation.
\end{abstract}

Keywords: Additional proposed dividend. ICPC 08. Value relevance.

\section{Resumen}

Sobre la base de la Teoría de Dividendos de señalización, que son vistos como indicadores de información sobre el mercado. Sin embargo, tras la adopción de IFRS muchas empresas hacer uso del Dividendo Adicional Propuesto (DAP), que, hasta la resolución de los accionistas, no se caracteriza por ser una obligación. En este contexto, el objetivo del estudio fue analizar la importancia de la difusión de la DAP para el mercado de capitales brasileño. A través de regresiones con datos de panel, entre 2010-2012, se encontró que el DAP influye en el precio de las acciones debido a su contenido informativo, revelando información útil para el mercado, de acuerdo con los estudios de área. Por lo tanto, como una contribución, el estudio muestra que la vista de los inversores, el aumento de la distribución de dividendos indica un signo positivo de mayores beneficios en el futuro, en consonancia con la Teoría de Dividendos de señalización, incluso si estos dividendos no tener la obligación fecha de presentación del balance general.

Palabras clave: Dividendo adicional propuesto. ICPC 08. Relevantes. 


\section{Introdução}

Este artigo traz evidências empíricas que confirmam a utilidade do Dividendo Adicional Proposto (DAP) para o mercado de capitais, resultado favorável à hipótese de sinalização estudada por Pettit (1972) e Miller e Rock (1985), na qual o dividendo é um mecanismo de transmissão de informação de boas oportunidades e crescimento futuro. Assim, este estudo revela o papel do DAP e suas consequências econômicas no contexto do mercado de capitais brasileiro, aspecto ainda não abordado pelas pesquisas nacionais.

Embora as empresas brasileiras tenham como principal fonte de financiamento as instituições financeiras, herança do sistema Civil Law, a emissão de ações no mercado de capitais também é uma forma de financiamento. No entanto, para manter sua representatividade como fonte de recurso, há a necessidade de disponibilização de informações transparentes, relevantes e confiáveis aos acionistas e investidores. Afinal, é por meio dessas informações que os usuários poderão avaliar o desempenho e continuidade da empresa, buscando aquelas que lhes proporcionarão maior retorno pela aplicação dos recursos. Nesse sentido, a divulgação das demonstrações contábeis pode diminuir a informação assimétrica, sendo capaz de influenciar as decisões econômicas dos usuários (YAMAMOTO; SALOTTI, 2006).

A título de exemplo tem-se a divulgação quanto aos dividendos. Há diversos incentivos para o estudo dos dividendos no Brasil, inclusive por aspectos de normatização como: a) a Lei $n^{\circ} 6.404$, de 1976, e a Lei $n^{\circ} 10.303$, de 2001, regulam a distribuição de dividendos no Brasil. A Comissão de Valores Mobiliários - CVM também é responsável, mas com autoridade residual por normatizar assuntos contábeis, dentre eles a distribuição de dividendos; b) além disso, nem todas as empresas estabelecem, precisamente, em seus estatutos o valor de dividendos a ser distribuído, como, por exemplo, MRV Engenharia, Estácio Participações, GTD Participações e QGEP Participações S.A. Nessas situações, a legislação torna-se base e estabelece um dividendo mínimo obrigatório de $25 \%$ sobre o lucro líquido ajustado; e c) por fim, deve-se considerar que, ao contrário do que ocorre em outros países, como nos Estados Unidos, no Brasil não há tributação sobre a distribuição de dividendos, aumentando sua relevância em termos de remuneração (ASSAF NETO; LIMA; AMBROZINI, 2007).

Nesse contexto, a partir de dezembro de 2010, e em 2009 para fins comparativos, conforme Deliberação 601/09, da CVM, que referenda a interpretação técnica ICPC 08 (R1) sobre "Contabilização da Proposta de Pagamento de Dividendos", uma nova informação passou a aparecer nas demonstrações contábeis: os dividendos adicionais propostos com base no ICPC 08 (R1). Esse dividendo é aquele que excede ao mínimo obrigatório, não indicando necessariamente uma obrigação presente. Essa conta deve ser divulgada no patrimônio líquido, cabendo à assembleia decidir sobre a sua efetiva distribuição. A respeito desse tipo de informação, tem-se que a divulgação da distribuição de dividendos é um momento aguardado pelos acionistas, já que, segundo Allen, Bernardo e Welch (2000), os investidores têm preferência pela compra de ações das empresas que distribuem dividendos.

Dada a importância dessa informação, alguns estudos analisam o impacto do conteúdo informacional dos dividendos. A título de exemplo, na pesquisa de Novis, Neto e Saito (2003), eles investigaram o preço das ações durante a divulgação da distribuição de dividendos, encontrando uma relação positiva entre essas variáveis. Esse artigo propõe a 
aplicação do método value relevance, ou, análise da relevância da informação contábil, pautado pelo paradigma positivo. Essa abordagem pode ser operacionalizada por meio de técnicas de associação, tal como análise de regressão, cuja variável dependente é o preço das ações, e as variáveis independentes são representadas pelas informações contábeis, como: patrimônio líquido e lucro líquido (BROWN; LO; LYS, 1999). A identificação de uma relação positiva entre as variáveis investigadas pode confirmar a importância da informação contábil para o mercado de capitais. Nesse sentido, Barth, Beaver e Landsman (2001) também afirmam que, se uma informação contábil tem impacto no preço das ações, se entende que ela é relevante para o mercado de capitais, exercendo influência sobre as decisões dos usuários.

Essa linha de pesquisa tem se desenvolvido com proeminência em países como Estados Unidos e Inglaterra, mas em volume inferior em países como o Brasil. Assim, com o intuito de contribuir para a literatura brasileira e procurando entender como o mercado reage diante do Dividendo Adicional Proposto, este artigo tenciona analisar a seguinte questão de pesquisa: A divulgação do dividendo adicional proposto pelas empresas brasileiras de capital aberto é relevante para o mercado de capitais? Portanto, o objetivo é analisar se a divulgação do dividendo adicional proposto tem impacto positivo no preço das ações das empresas brasileiras de capital aberto, contribuindo com os estudos da área.

Assim, este trabalho apresenta os principais aspectos teóricos sobre o tema na seção 2. Em seguida, na seção 3, tem-se a metodologia, métodos e modelos utilizados para a realização do estudo. Na seção 4, apresentam-se e comentam-se os resultados encontrados. Por fim, na seção 5, estão as considerações finais e as limitações da pesquisa.

\section{Referencial Teórico}

\subsection{Teorias de Dividendos}

Freire et al. (2005) trazem à discussão a premissa de que os gestores devem sempre vislumbrar que o objetivo da empresa é maximizar o valor para os acionistas. Desse modo, suscitam uma questão central nessa temática: o índice de distribuição ideal da preferência dos investidores por dividendos versus os ganhos de capital. Para responder a essa questão destacam a importância de entender três teorias de preferência do investidor: Teoria da Irrelevância dos Dividendos, Teoria do Pássaro na Mão e Teoria da Preferência Tributária (FREIRE et al., 2005). As discussões, a seguir, visam detalhar essas teorias.

Os trabalhos clássicos de Lintner (1956) e Miller e Modigliani (1961) visam explicar a influência do pagamento de dividendos sobre o valor das empresas. Lintner (1956) concluiu que os dividendos do período anterior têm impacto positivo nos dividendos atuais, pois as empresas aumentam ou diminuem o volume de dividendos distribuídos menos do que proporcionalmente à variação de seus ganhos por ação, para manterem certa estabilidade em relação ao que vem sendo distribuído em períodos anteriores. O autor verificou ainda que as alterações na política de dividendos enviam sinais positivos ou negativos ao mercado, por isso a relutância em diminuir os dividendos, pois essa ação gera um sinal negativo para o mercado.

Por sua vez, Miller e Modigliani (1961) revelaram que, em mercados perfeitos, ou seja, onde não há impostos e custos de transação, a política de dividendos não afeta o valor das empresas, sendo irrelevante. Assim, as decisões dos administradores de pagar dividendos não são capazes de afetar o valor das ações. Esse artigo deu origem à Teoria da Irrelevância 
dos Dividendos, em que as diferenças entre as políticas de dividendos praticadas não são capazes de interferir no valor de mercado da empresa.

Santana (2006) complementa o trabalho de Miller e Modigliani (1961), definindo premissas para explicar a irrelevância dos dividendos, tais como: i) o valor da empresa depende apenas da capacidade de geração de lucros e dos riscos dos ativos; ii) caso os dividendos afetem o valor da empresa, isso ocorre em função do conteúdo informacional (sinalização), devido às expectativas de ganhos futuros, levando a acréscimos nos preços das ações; e iii) ocorrência de um efeito clientela que leva os acionistas a receberem os dividendos que esperam, pois há investidores que preferem investimentos estáveis e previsíveis como fonte de renda; assim, eles buscam ações que pagam o mesmo montante de dividendos a cada período. Por outro lado, aqueles que preferem ganhos de capital são atraídos por empresas em fase de crescimento que reinvestem grande parcela de seus lucros, revelando um padrão instável no pagamento dos dividendos.

Contrariando a Teoria da Irrelevância dos Dividendos, Gordon (1963) e Lintner (1962) desenvolveram a teoria na qual se prevê uma relação direta entre política de dividendos da empresa e seu valor de mercado. Eles afirmam que os investidores evitam os riscos em situações de incerteza, ou seja, preferem dividendos correntes a dividendos futuros ou ganhos de capital. O retorno ao acionista é menor conforme aumenta a distribuição de dividendos, tendo em vista a maior certeza em receber dividendos presentes, se comparado ao eventual ganho de capital futuro. Tal observação foi intitulada de Teoria do Pássaro na Mão, fundamentando um dos principais tópicos sobre relevância da informação contábil. Nesse sentido, Pettit (1972) e Miller e Rock (1985) também contribuíram para o surgimento da Teoria da Sinalização dos Dividendos, com a hipótese de que os dividendos são um dos sinalizadores de informações. Assim, o aumento na distribuição dos dividendos pode indicar, para os investidores, um sinal positivo de que lucros maiores serão realizados no futuro, enquanto a diminuição dos dividendos pode mostrar incertezas sobre o futuro da empresa.

Outro artigo sobre a relação entre mudança da política de dividendos e a lucratividade futura é o de Nissim e Ziv (2001). Eles verificaram que as mudanças de dividendos sinalizam alterações nos ganhos futuros a partir dos dois anos seguintes à alteração na política de dividendos. Embora não haja uma política de dividendos definitiva, os autores afirmam que é possível definir uma política ótima, obtendo um equilíbrio entre os dividendos correntes e o crescimento futuro, com o intuito de maximizar o preço das ações da empresa. Brigham, Gapenski e Ehrhardt (2001) afirmam que não é possível definir a preferência dos investidores por dividendos mais elevados ou baixos, pois alguns preferem ganho de capital, e outros, dividendos. Corroborando essa ideia, González (1998) define uma política de dividendos como uma decisão de financiamento e afirma que uma relação ótima seria a política de dividendos que integra, da forma mais acertada possível, a quantidade a ser retida pela empresa e a quantidade de dividendos que será distribuída aos acionistas.

Uma terceira teoria é a da Preferência Tributária, que teve como principais expoentes Brennan (1970) e Litzenberger e Ramaswamy (1979). Ela é definida

[...] em um mercado em que os dividendos são tributados a uma alíquota maior do que os ganhos de capital, como o americano, o investidor preferirá uma política de dividendos que tenha a menor distribuição possível, uma vez que a carga tributária consumirá parte substancialmente maior do seu rendimento (MARTINS; FAMÁ, 2012, p. 26). 
A esse respeito, Bueno (2000) explica ainda que, mesmo que as alíquotas de tributação para dividendos e ganhos de capital fossem iguais, existiria o benefício do desembolso, pois os impostos sobre dividendos são pagos quando do seu recebimento, enquanto que, nos ganhos de capital, se paga apenas na realização do lucro, ou seja, no momento em que as ações forem vendidas. Essa teoria é oposta à Teoria do Pássaro na Mão e mais radical que a Teoria da Irrelevância, uma vez que tem fundamentos em regras de imposto de renda e no modo divergente como são tratados dividendos e ganhos de capital (BUENO, 2000).

Em contrapartida, Loss e Sarlo Neto (2003) dizem que é possível encontrar no mercado aqueles investidores que, independentemente de efeitos tributários, precisam receber dividendos, e aqueles que não necessitam, aludindo à hipótese da clientela de dividendos:

[...] de acordo com a política de dividendos adotada cada entidade atrairá os investidores que dela se agradarem. Se os investidores encontram ações que correspondem às suas preferências, o equilíbrio é atingido e o valor das ações não é afetado pela política de dividendos (LOSS; SARLO NETO, 2003, p. 47).

Com relação ao Brasil, Diehl et al. (2010) afirmam que o interesse pelo estudo dos dividendos evoluiu principalmente por estes quatro fatores:

1. Período precedente à inflação: até então, o dividendo era tido como algo sem importância, já que seu valor monetário era corroído pelos efeitos da inflação.

2. Período pós-estabilização (após 1994): o investidor começa a perceber valor no dividendo e a entendê-lo como parte do retorno das ações.

3. Exuberância do mercado acionário brasileiro: há um encantamento do investidor em função dos ganhos de capital auferidos no período de significativo crescimento da Bolsa de Valores em detrimento à importância dos dividendos.

4. Governança corporativa: a política de dividendos é um relevante fator de governança corporativa, em paralelo à composição acionária e à transparência das demonstrações contábeis.

\subsection{Teoria Positiva da Contabilidade e Value relevance}

Ao final dos anos 1960, a pesquisa em Contabilidade, tradicionalmente normativa, passou a adotar uma abordagem voltada para a informação, conhecida como informational approach, cujos estudos avaliam a capacidade da informação em ser útil para a tomada de decisão de seus usuários. As pesquisas preocupavam-se com a avaliação de práticas contábeis mais adequadas para as empresas, baseadas em conceitos econômicos de lucro e riqueza (LOPES, 2002). Nesse contexto, Beaver (1968) e Ball e Brown (1968) deram início aos estudos positivistas, evidenciando o impacto da informação contábil no preço das ações.

A partir desse momento, a literatura contábil adotou a premissa de que a Contabilidade é uma fonte de informações para o mercado de capitais, utilizando esse paradigma para investigar as relações entre a contabilidade e os preços das ações (YAMAMOTO; SALOTTI, 2006). Essa linha de pesquisa positivista foi consolidada após a divulgação da obra de Watts e Zimmerman (1986), que apresentou hipóteses para explicar variações no processo contábil das empresas, as quais são fundamentadas por incentivos distintos entre as partes.

Com isso, os estudos de value relevance passaram a analisar se a informação contábil provocava alguma reação no mercado de capitais. Segundo esse método, um número contábil será considerado relevante somente se refletir informações relevantes aos investidores na 
avaliação das empresas (FRANCIS; SCHIPPER, 1999; HOLTHAUSEN; WATTS, 2001). Por exemplo, Collins, Maydew e Weiss (1997) investigaram as mudanças sistemáticas na relevância, ou value relevance, do lucro e do patrimônio líquido ao longo do tempo, identificando que i) um aumento na relevância do efeito combinado PL e no lucro nos últimos 40 anos; ii) a análise individual revelou que a relevância do PL tem aumentado, enquanto a do lucro líquido tem diminuído; e iii) houve um aumento na relevância incremental do PL durante o período de análise. Uma explicação para esses resultados baseia-se em aumento de itens extraordinários, maior frequência de prejuízos, crescimento do número de empresa de pequeno porte na Bolsa de Valores e aumento da relevância de empresas do ramo de serviço e de alta tecnologia. A fundamentação teórica para o trabalho é o modelo Residual Income Valuation (RIV), de Ohlson (1995), no qual se demonstra matematicamente a precificação das empresas em função das variáveis contábeis, cujos lucros são a base de cálculo para o valor da empresa.

Outros trabalhos que merecem destaque são: i) Rees (1997) e Brief e Zarowin (1999), sugerindo a relevância dos dividendos e do conteúdo informacional; ii) Francis e Schipper (1999), que exploram a relevância de uma informação contábil e sua capacidade de capturar informações que impactam os preços das ações; iii) Barth, Beaver e Landsman (2001), os quais consideram que as pesquisas de value relevance têm como foco verificar se a informação contábil reflete, minimamente, o preço das ações no mercado de capitais, demonstrando a importância dos estudos dessa natureza no estabelecimento de padrões e normas contábeis; e iv) Houlthausen e Watts (2001), que apontaram a falta de uma teoria de base ou pronunciamentos conceituais técnicos e regulatórios na fundamentação das pesquisas sobre a importância do value relevance. De um modo geral, o que se ressalta é que a informação contábil vem adquirindo espaço significativo na composição das variáveis dos modelos de avaliação. Em outras palavras, a Contabilidade torna-se indispensável no processo de realização de avaliações e previsões econômicas das empresas.

\subsection{Evidências Empíricas da Relevância da Informação Contábil e dos Dividendos}

O objetivo desta seção é trazer alguns trabalhos que investigaram a relevância da informação contábil, além dos próprios dividendos. Espera-se que o novo modelo contábil adotado pelo Brasil a partir de 2010, baseado nas Internacional Financial Reporting Standards - IFRS, contribua para a apresentação de demonstrações contábeis relevantes para fins de decisão, inclusive as informações referentes à distribuição de dividendos. Nesse contexto, destaca-se o ICPC 08 (R1) - Contabilização da Proposta de Pagamento de Dividendos, que pode ganhar espaço significativo entre as informações usadas pelos investidores.

Nessa linha, pode-se citar o trabalho de Schiehll (1996), que avaliou se a divulgação das demonstrações contábeis impacta no mercado de capitais, utilizando-se como metodologia o estudo de eventos. Os resultados sugerem que a divulgação dessas demonstrações é relevante, já que os retornos anormais, em torno da data do evento, foram estatisticamente expressivos. Utilizando a mesma metodologia, Bernardo (2001) pesquisou a reação dos investidores ao anúncio das demonstrações contábeis por meio do comportamento dos retornos anormais das ações nas datas próximas à publicação, durante o período de maio de 1995 a janeiro de 2001. O autor concluiu que os investidores, ao se depararem com uma informação de caráter desfavorável, atribuem um resultado negativo a ela. Também foi 
constatado que os preços das ações, em torno da data da publicação dos relatórios, são consistentes com a forma semiforte de eficiência de mercado, proposta por Fama (1970). Portanto, as demonstrações contábeis, representadas pela figura do lucro por ação, demonstram ter conteúdo informacional.

Outras pesquisas oferecem resultados semelhantes: i) Loriato e Gomes (2006) identificaram que divulgações contábeis anuais revelam informações relevantes para o mercado brasileiro, provocando um aumento no volume de ações negociadas, especialmente próximo da semana do anúncio; ii) Sarlo Neto, Lopes e Costa (2006) utilizaram a metodologia de Beaver (1968) e variância dos retornos anormais, verificando que a divulgação das demonstrações tem impacto sobre o preço das ações, sugerindo que essas informações possuem conteúdo informacional relevante para o mercado de capitais; iii) Scarpin, Pinto e Boff (2007) constataram que a data de publicação dos relatórios, além de variáveis contábeis, influenciaram o preço da ação e o volume de negócios; e iv) Silva e Fávero (2007) identificaram que o desempenho da empresa e os dividendos distribuídos são fatores que explicam a variação de seus preços, mais precisamente para ações ordinárias, diferentemente das ações americanas.

Recentemente, Brugni et al. (2012), baseados no trabalho de Francis, Schipper e Vicent (2005), obtiveram evidências de que os dividendos contribuem positivamente para a informatividade do lucro como variável explicativa do retorno das ações.

Assim, pode-se dizer que essas pesquisas, com metodologias e épocas diferentes, são congruentes em indicar que o conteúdo informacional da contabilidade é percebido pelo mercado de capitais. Complementarmente, Castro e Marques (2013) perceberam uma nova visão em relação à informação contábil, decorrente da evolução das pesquisas na área. Segundo os autores

[...] as recorrentes pesquisas reforçaram a hipótese de que essas informações tornaram-se base para a tomada de decisões pelos investidores, que utilizam os demonstrativos para projetar suas perspectivas em relação ao futuro da empresa e seu comportamento no mercado (CASTRO; ALVES; 2013, p. 111).

Adicionalmente, há um conjunto de pesquisas voltado para o estudo do impacto da política de dividendos e seu conteúdo informacional no mercado de capitais. Por exemplo, Figueiredo (2002) identificou, para o período de 1986 a 2000, que as alterações na política de dividendos não contêm informações sobre o desempenho futuro das empresas. Contudo, surgiram outros estudos empíricos sobre a política de dividendos, com base no conceito da condução de informação, sugerindo que o lucro distribuído é um dos fatores que podem influenciar o preço das ações, de acordo com Procianoy e Verdi (2003), Freire e Lima (2003) e Kuronuma, Lucchesi e Famá (2004).

Outros estudos podem ser citados, nessa linha, como: i) Novis Neto e Saito (2003) que encontraram uma relação direta e positiva entre o dividend yield e o retorno anormal acumulado no período pós-pagamento de dividendos; além disso, os autores observaram que a distribuição de dividendos é uma forma de redução de assimetria informacional entre os investidores, aumentado o valor da empresa; ii) Loss e Sarlo Neto (2003) verificaram que, quando a distribuição de dividendos aumenta, o mercado tende a reagir positivamente, mas uma redução tem o efeito contrário; e iii) Ambrozini (2011) constatou que as empresas atribuem à política de dividendos menor grau de importância quando se trata de decisão sobre dividendos. 
Brugni et al. (2012) destacam que no Brasil, bem como na maior parte dos países com mercado de capitais menos desenvolvidos, quando comparados com os Estados Unidos, Inglaterra e Austrália, relativamente são poucos os trabalhos que visam estudar o poder explicativo e preditivo das variáveis contábeis, suas relações entre si e com o retorno das ações.

Mais recentemente, Sobrinho, Rodrigues e Sarlo Neto (2014) estudaram as empresas brasileiras de capital aberto com base na hipótese de que as empresas pagadoras de dividendos possuem menor gerenciamento de resultado. Os achados indicam que as empresas que realizam maiores pagamentos de dividendos estão associadas a maiores níveis de gerenciamento de resultados, contrariando a hipótese investigada.

Complementarmente, Melo e Fonseca (2015) estudaram as empresas que distribuíram lucro na forma de dividendos ou Juros sobre Capital Próprio - JCP, após divulgação de fato relevante ou não. Independentemente dessa divulgação, os autores constatam a presença de retorno anormal com a aplicação de estudo de evento, evidenciando mudança no comportamento das ações com base nas informações divulgadas.

Por sua vez, Vancin e Procianoy (2016) constataram que, em média, 63,3\% das empresas brasileiras de capital aberto pagaram dividendos acima do mínimo obrigatório, indicando que a maioria das empresas brasileiras utiliza o pagamento do Dividendo Adicional Proposto (DAP). Os autores relataram que essas empresas têm maiores níveis de Return on Equity ( $R O E$ ), liquidez, tamanho, estabilidade na política de dividendos, além de menores níveis de investimentos e instabilidade de receitas. Esses resultados são coerentes com a teoria residual de dividendos, ou seja, a existência de excesso de lucros retidos implica a distribuição de dividendos.

Nesse contexto, em economias emergentes, destacam-se duas pesquisas: i) no Kuwait, Al-Hares, AbuGhazaleh e Haddad (2012) investigaram a relevância da informação contábil no período de 2003 a 2009, com destaque para lucro, patrimônio líquido e dividendo; os autores observaram que o dividendo é uma informação relevante quando não analisado em conjunto com lucro líquido; e ii) Omokhudu e Ibadin (2015) analisaram a relevância da informação contábil na Nigéria, com destaque para lucro, fluxo de caixa e dividendos, os quais se mostraram de maior utilidade para os investidores.

Esses estudos podem ser resumidos no Quadro 1.

\section{Quadro 1 - Pesquisas relacionadas a dividendos}

\begin{tabular}{|c|c|}
\hline Autores & Resultados \\
\hline Figueiredo (2002) & $\begin{array}{l}\text { Alterações na política de dividendos não contêm } \\
\text { informações sobre o desempenho futuro das empresas. }\end{array}$ \\
\hline $\begin{array}{l}\text { Procianoy e Verdi (2003), Freire e Lima (2003), } \\
\text { e Kuronuma, Lucchesi e Famá (2004) }\end{array}$ & $\begin{array}{l}\text { A política de dividendos é um dos fatores que pode } \\
\text { influenciar o preço das ações. }\end{array}$ \\
\hline Novis Neto e Saito (2003) & $\begin{array}{l}\text { A distribuição de dividendos é uma forma de redução } \\
\text { de assimetria informacional entre os investidores, } \\
\text { aumentado o valor da empresa. }\end{array}$ \\
\hline Loss e Sarlo Neto (2003) & $\begin{array}{l}\text { Quando a distribuição de dividendos aumenta, o } \\
\text { mercado tende a reagir positivamente. }\end{array}$ \\
\hline Silva e Fávero (2007) & Dividendos influenciam preços das ações. \\
\hline Ambrozini (2011) & $\begin{array}{l}\text { A política de dividendos recebe menor grau de } \\
\text { importância das empresas. }\end{array}$ \\
\hline Al-Hares, AbuGhazaleh e Haddad (2012) & $\begin{array}{l}\text { O dividendo é uma informação relevante quando não } \\
\text { analisado em conjunto com lucro líquido. }\end{array}$ \\
\hline Brugni et al. (2012) & Os dividendos influenciam retorno das ações. \\
\hline
\end{tabular}




\begin{tabular}{|l|l|}
\hline Sobrinho, Rodrigues e Sarlo Neto (2014) & $\begin{array}{l}\text { Maiores pagamentos de dividendos estão associados a } \\
\text { elevados níveis de gerenciamento de resultado. }\end{array}$ \\
\hline Melo e Fonseca (2015) & $\begin{array}{l}\text { A divulgação de fato relevante ou não sobre dividendos } \\
\text { ou JCP provoca alteração no comportamento das ações. }\end{array}$ \\
\hline Omokhudu e Ibadin (2015) & $\begin{array}{l}\text { Os dividendos possuem conteúdo informacional para } \\
\text { os investidores. }\end{array}$ \\
\hline Vancin e Procianoy (2016) & $\begin{array}{l}\text { A existência de excesso de lucros retidos implica } \\
\text { distribuição de dividendos. }\end{array}$ \\
\hline
\end{tabular}

Fonte: Elaborado pelos autores.

O Quadro 1 mostra diversos estudos sobre a relação entre a distribuição de dividendos e o comportamento dos investidores, analisado por meio de dados do mercado de ações. Contudo, nenhum deles investigou o efeito informacional proporcionado pelo ICPC 08 (R1) que trata do Dividendo Adicional Proposto, o que caracteriza o ineditismo deste trabalho.

Assim, com base nesses achados sobre a relevância da informação contábil, e considerando que o processo de convergência às IFRS caminha para a divulgação de demonstrações contábeis mais relevantes, pode-se definir a hipótese de pesquisa:

$\mathrm{H}_{1}$ : o Dividendo Adicional Proposto é relevante para o mercado de capitais brasileiro.

\section{Metodologia}

Este trabalho está inserido dentro de uma das áreas mais estudadas em finanças, ou seja, o papel da informação nos mercados de capitais com abordagem positivista, a qual, segundo Lopes e Martins (2005), está direcionada a compreender o porquê da contabilização de dado item e não indicar se ela é boa ou ruim, portanto tem o intuito em dar maior importância ao papel da informação contábil para seus usuários. O estudo encaixa-se no grupo sobre os estudos de conteúdo informacional marginal, proposto por Houlthausen e Watts (2001), pois o objetivo é estudar se o dividendo adicional proposto agrega informações aos investidores, observando o preço das ações das empresas.

Para realização da pesquisa, foi utilizada a abordagem metodológica de Collins, Maydew e Weiss (1997), fundamentada pelo modelo de Ohlson (1995). Esse estudo utiliza as variáveis lucro, patrimônio e dividendo adicional proposto na explicação da relevância para o mercado de capitais. Além disso, algumas variáveis de controle foram adicionadas com o propósito de diminuir o problema de variáveis omitidas, as quais estão descritas a seguir, juntamente com o modelo base, conforme Equação 1:

$$
P_{i t}=\alpha+\alpha_{1} L L_{i t}+\alpha_{2} P_{i t}+\alpha_{3} T_{A M}+\alpha_{4} \text { CRESC }_{i t}+\alpha_{5} \text { ENVID }_{i t}+\alpha_{6} A D R_{i t}+\sum_{j}^{j-1} \varphi_{j} S E T O R+\varepsilon_{i t}
$$

Equação 1

onde $P_{i t}$ é o preço da ação da empresa $i$ três meses após o final do ano fiscal $t ; L L_{i t}$ é o lucro por ação da empresa $i$ no ano $t ; P L_{i t}$ é o patrimônio líquido por ação da empresa $i$ no ano $t ; T A M_{i t}$ é o logaritmo natural do ativo da empresa $i$ no ano $t ; C R E S C_{i t}$ é a variação da receita em $t$ em relação à $t-1$ para a empresa $i ; E N D I V_{i t}$ é dada pela relação entre a dívida total e o ativo da empresa $i$ para o ano $t$; $A D R_{i t}$ é uma dummy que assume 1 (um) se a empresa $i$ possui 
American Depositary Receipt (ADR) na New York Stock Exchange (NYSE) para o período $t$, e 0 (zero) caso contrário; SETOR corresponde a dummies adicionadas para controlar o efeito setor; $\varepsilon_{i t}$ é o termo de erro da empresa $i$ no ano $t$. As variáveis $P i t, L L_{i t}, P L_{i t}$ foram divididas pelo preço da ação em $t-1$ para reduzir problemas de escala, conforme sugestão de Brown, Lo e Lys (1999).

Considerando que o objetivo é estudar o efeito do dividendo adicional proposto, foi necessário isolar esse valor por meio do ajuste no modelo da Equação 1, conforme apresentado na Equação 2:

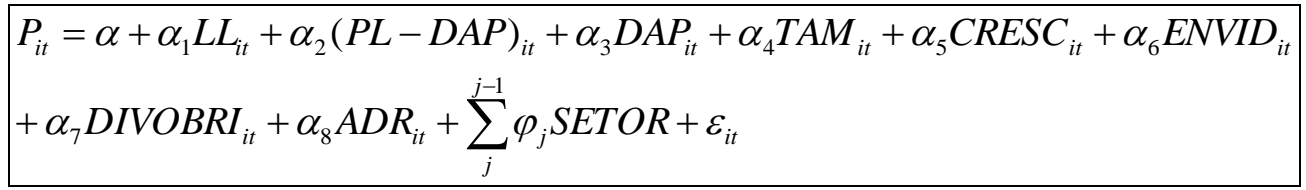

\section{Equação 2}

onde $(P L-D A P)_{i t}$ é o patrimônio líquido, sem o efeito do dividendo adicional proposto, dividido pela quantidade de ações da empresa $i$ no ano $t$; $D A P_{i t}$ é o dividendo adicional proposto da empresa $i$ no ano $t$; DIVOBRIG $G_{i t}$ é o dividendo obrigatório a pagar constante no passivo da empresa $i$ no ano $t$, dividido pelo lucro em $t$; $\varepsilon_{i t}$ é o termo de erro da empresa $i$ no ano $t$. As variáveis $P_{i t}, L L_{i t}, P L-D A P_{i t}$ e $D A P_{i t}$ também foram divididas pelo preço da ação em t-1 para reduzir problemas de escala, conforme sugestão de Brown, Lo e Lys (1999).

Em seguida, o modelo foi decomposto em outras três Equações (Equação 3, 4 e 5) para testar a relevância da informação contábil com base no lucro líquido, do patrimônio líquido sem o efeito do dividendo adicional proposto e do próprio dividendo adicional proposto isoladamente.

$$
\begin{gathered}
\frac{P_{i t}=\alpha+\alpha_{1} L L_{i t}+\varepsilon_{i t}}{\text { Equação } 3} \\
\frac{P_{i t}=\alpha+\alpha_{1}(P L-D A P)_{i t}+\varepsilon_{i t}}{\text { Equação } 4} \\
\frac{P_{i t}=\alpha+\alpha_{1} D A P_{i t}+\varepsilon_{i t}}{\text { Equação } 5}
\end{gathered}
$$

A amostra foi composta por empresas brasileiras de capital aberto, listadas na BM\&FBOVESPA, cujas demonstrações contábeis datam de 2010, 2011 e 2012 e que divulgaram dividendo adicional proposto (DAP), localizado no patrimônio líquido. Os dados foram obtidos no Economática, e as empresas que não apresentaram DAP foram excluídas, resultando em amostra final de 102 empresas. Consequentemente, a amostra é não probabilística, implicando a impossibilidade de generalizar os resultados para a população (MARTINS; THEÓPHILO, 2009). Por último, a aplicação dos testes foi realizada pelo software estatístico Stata/SE 10.1.

Deve-se fazer uma ressalva quanto à divulgação dos dividendos adicionais propostos, que para algumas empresas não foi adequada, visto que o detalhamento em nota explicativa da destinação do lucro apurado no exercício não foi suficiente para compreender o valor 
proposto, muito menos a importância definida após deliberação tomada pelos sócios (ICPC 08, R1).

A confirmação da hipótese de pesquisa depende dos resultados apresentados para a variável Dividendo Adicional Proposto (DAP), presente nas Equações 2 e 5 . O sinal positivo e a significância estatística fornecem indícios de que o DAP é relevante para os acionistas. Além disso, esse resultado é coerente com o estudo de Lintner (1956) e a hipótese de sinalização, cujo aumento nos dividendos pode ser entendido como um mecanismo de transmissão de oportunidades de crescimento e investimento. Contudo, não há consenso sobre a capacidade de os dividendos influenciarem o valor de mercado das companhias brasileiras (AMBROZINI, 2011).

\section{Apresentação e Análise dos Resultados}

\subsection{Análise do Comportamento dos Dados}

No Quadro 2, apresenta-se a estatística descritiva das variáveis utilizadas na pesquisa.

Quadro 2 - Estatística descritiva para os valores contábeis brutos (em milhares R\$) e preço da ação

\begin{tabular}{|l|c|c|c|c|c|c|}
\hline & \multicolumn{2}{|c|}{2010} & \multicolumn{2}{c|}{2011} & \multicolumn{2}{c|}{2012} \\
\hline & Média & Desvio padrão & Média & Desvio padrão & Média & Desvio padrão \\
\hline P & 25 & 41 & 28 & 38 & 31 & 51 \\
\hline PL & 557.068 & 1.032 .539 & 595.851 & 1.223 .043 & 458.863 & 1.514 .711 \\
\hline DAP & 3.546 .811 & 8.258 .266 & 4.154 .967 & 9.728 .605 & 4.244 .080 & 9.223 .976 \\
\hline Ativo & 150.231 & 485.416 & 131.341 & 298.057 & 128.062 & 382.281 \\
\hline Receita & 10.290 .162 & 31.453 .320 & 11.768 .853 & 35.530 .514 & 13.367 .359 & 40.855 .790 \\
\hline Dívida total & 3.835 .937 & 6.283 .571 & 4.235 .016 & 7.270 .171 & 4.945 .919 & 8.536 .443 \\
\hline $\begin{array}{l}\text { Dividendos } \\
\text { obrigatórios }\end{array}$ & 90.825 & 338.699 & 125.378 & 505.570 & 151.034 & 612.322 \\
\hline
\end{tabular}

Nota: $P$ é o preço das ações 3 meses após o encerramento do ano fiscal $t ; L L$ é o lucro líquido em $t ; P L$ é o patrimônio líquido em $t$; DAP é o Dividendo Adicional Proposto em $t$; Ativo corresponde ao ativo total em $t$; Receita é a receita líquida de vendas em $t$; Dívida total abrange os passivos onerosos como empréstimos, financiamentos, debêntures etc. em $t$; Dividendos obrigatórios são os dividendos contabilizados no passivo em $t$. Fonte: Dados da pesquisa.

Os dados do Quadro 2 revelam que, em média, houve um crescimento das empresas dado pelo aumento no preço das ações, PL, Ativo, Receita e Dívida Total, enquanto que o lucro líquido apresentou uma redução em 2012 de $23 \%$. Apesar disso, o passivo "dividendos obrigatórios" aumentou ao longo do período estudado, indicando que, em média, a queda do lucro não restringiu o aumento na distribuição de dividendos. Essa constatação está coerente com a dificuldade de reduzir o percentual de distribuição de lucros devido à resistência dos acionistas que se acostumam com um payout maior (AMBROZINI, 2011).

Por outro lado, o dividendo adicional proposto caiu quase $15 \%$ ao longo do período estudado. A distribuição do DAP depende do desempenho econômico financeiro da empresa, 
da necessidade de retenção de recursos para a realização de investimentos, além de outros fatores que não são controlados pela gestão, como as variáveis macroeconômicas que podem ser favoráveis ou desfavoráveis à distribuição de riqueza nas companhias. Com isso, um lucro elevado não indica necessariamente que um prêmio será concedido aos acionistas pelo desempenho superior da companhia.

Posto isso, uma maneira de entender a redução do DAP pode ser pela análise do mercado de ações, representado pelo IBOVESPA. Segundo a BM\&FBOVESPA, esse índice indica o "desempenho médio das cotações dos ativos de maior negociabilidade e representatividade do mercado de ações brasileiro" (BM\&FBOVESPA, 2015). Observa-se uma redução no IBOVESPA para o período de 2010 a 2012, conforme Quadro 3.

Quadro 3 - Comportamento IBOVESPA para 2010-2012

\begin{tabular}{|c|c|c|}
\hline & Pontos IBOVESPA & \% IBOVESPA \\
\hline 2010 & $67.276,75$ & - \\
\hline 2011 & $61.317,43$ & $-8,86 \%$ \\
\hline 2012 & $59.621,31$ & $-2,77 \%$ \\
\hline
\end{tabular}

Nota: Inicialmente calculou-se a média mensal com base nos pontos diários, e depois disso a média dos 12 meses do ano-calendário, que corresponde à média anual.

Fonte: BM\&FBOVESPA - http://www.bmfbovespa.com.br/.

Ao tomar esse índice como uma proxy da carteira de mercado, uma queda no IBOVESPA pode representar uma queda no desempenho das companhias abertas. Nesse sentido, a redução no IBOVESPA está coerente com a queda do DAP, visto que a predisposição da administração em distribuir Dividendos Adicionais diminuiria em cenários de menor desempenho.

Ademais, podemos assumir que o IBOVESPA possui relação com as variáveis macroeconômicas (NUNES; COSTA JÚNIOR; MEURER, 2005; GRÔPPO, 2006; SILVA; CORONEL, 2012), o que ajuda a explicar o desempenho do índice. Sua redução está coerente com o desempenho da economia brasileira no período de 2010 a 2012, que sofreu uma desaceleração no primeiro mandato do governo de Dilma Rousseff (CAGNIN et al., 2013). Além disso, o cenário externo foi desfavorável, considerando as quedas nos preços das commodities e menor demanda por exportações (QUEIROZ; CRUZ, 2014).

Por fim, uma análise de correlação de Pearson constatou uma relação fraca entre lucro e dividendo obrigatório, da ordem de 0,02 , enquanto a correlação entre lucro e Dividendo Adicional Proposto é forte, de aproximadamente 0,68. Esse resultado mostra que as variações do DAP tendem a acompanhar o comportamento do lucro líquido. O desvio padrão significativo em todas as variáveis deve-se à heterogeneidade das empresas na amostra.

\subsection{Resultados Empíricos}

O Quadro 4 apresenta os resultados para as cinco equações descritas na seção 3, que explicam o comportamento do preço das ações com base nas variáveis: lucro líquido, patrimônio líquido sem efeito do dividendo adicional proposto e dividendo adicional proposto isoladamente, além das variáveis de controle. 


\begin{tabular}{|l|c|c|c|c|c|}
\multicolumn{7}{|c|}{ Quadro 4 - Estimativas das Equações 1 a 5 } \\
\hline & Equação 1 & Equação 2 & Equação 3 & Equação 4 & Equação 5 \\
\hline$L L$ & $424,62^{* *}$ & 331,41 & $673,05^{*}$ & & \\
\hline$P L$ & $193,78^{* * *}$ & & & $280,50^{*}$ & \\
\hline$P L-D A P$ & & $190,78^{* * *}$ & & & \\
\hline$D A P$ & & 417,10 & & & $833,76^{* *}$ \\
\hline$T A M$ & $-0,43^{*}$ & $-0,45^{*}$ & & & \\
\hline$C R E S C$ & $0,25^{*}$ & $0,28^{*}$ & & & \\
\hline ENDIV & 0,52 & 0,50 & & & \\
\hline DIVOBRIG & & $-0,13$ & & & \\
\hline$N$ & 194 & 189 & 210 & 210 & 210 \\
\hline$F$ & $5,69^{*}$ & $8,55^{*}$ & $10,93 *$ & $14,18^{*}$ & $5,06^{* *}$ \\
\hline Especificação & Efeitos fixos & Efeitos fixos & Efeitos fixos & Efeitos fixos & Efeitos fixos \\
\hline
\end{tabular}

*significante a $1 \%$; **significante a $5 \%$; ***significante a $10 \%$.

Nota: $P_{i t}$ é o preço da ação da empresa $i$ três meses após o final do ano fiscal $t ; L L_{i t}$ é o lucro por ação da empresa $i$ no ano $t ; P L_{i t}$ é o patrimônio líquido por ação da empresa $i$ no ano $t ;(P L-D A P)_{i t}$ é o patrimônio líquido, sem o efeito do Dividendo Adicional Proposto, dividido pela quantidade de ações da empresa $i$ no ano $t ; D A P_{i t}$ é o Dividendo Adicional Proposto da empresa $i$ no ano $t$; TAM $i t$ é o logaritmo natural do ativo da empresa $i$ no ano $t$; $C_{R E S C} C_{i t}$ é a variação da receita em $t$ em relação à $t-1$ para a empresa $i$; $E N D I V_{i t}$ é dada pela relação entre a dívida total e o ativo da empresa $i$ para o ano $t$; DIVOBRI ${ }_{i t}$ é o dividendo obrigatório a pagar constante no passivo da empresa $i$ no ano $t$, dividido pelo lucro em $t$. As variáveis $P_{i t}, L L_{i t}, P L_{i t},(P L-D A P)_{i t}$ e $D A P_{i t}$ foram divididas pelo preço da ação em $t-1$ para reduzir problemas de escala, conforme sugestão de Brown, Lo e Lys (1999).

Fonte: Dados da pesquisa.

A Equação 1 foi estimada para verificar a relevância da informação contábil no mercado de capitais brasileiro, restringindo para a amostra de empresas analisadas. O teste de Hausman indicou que a abordagem de efeitos fixos é mais adequada para o conjunto de dados observados, o que impossibilita o uso de variáveis que se repetem ao longo dos períodos analisados como ADR e SETOR.

Além disso, foi detectado um problema de heterocedasticidade, sendo corrigido pelo teste de Newey West que, segundo Gujarati (2000), gera estimadores eficientes. Os erros padrão corrigidos são conhecidos como erros padrão consistentes para heterocedasticidade e autocorrelação. Com relação à multicolinearidade, não foram detectados problemas.

Após as verificações dos pressupostos, podem-se analisar os coeficientes estimados pela regressão, os quais indicam uma forte relação entre $L L$ e Preço das ações, visto que o coeficiente é significante estatisticamente a 5\%. Essa evidência é favorável à relevância da contabilidade para o mercado de capitais, coerente com outros trabalhos no mesmo contexto, tais como os de Lopes (2001), Almeida (2010), Lima (2011), Silva (2013) e Santos e Cavalcante (2014). Observe-se que embora o resultado geral da pesquisa de Santos e Cavalcante (2014) não permita afirmar que a adoção das IFRS no Brasil contribuiu com o aumento da relevância informacional do lucro contábil, os testes de capacidade associativa indicam aumento na relação entre retorno e números contábeis como lucro e patrimônio líquido. A relação fraca entre $P L$ e Preço das ações também foi observada em outros estudos, por exemplo, nos de Santos e Cavalcante (2014) e Silva e Nardi (2014). Estes últimos apresentaram uma possível explicação para a não significância estatística do patrimônio líquido. Segundo os autores, a conta "Ajuste de Avaliação Patrimonial" reflete aumentos no 
$P L$ que não transitaram pelo resultado. O saldo dessa conta é transferido para o resultado à medida que ativos e passivos são realizados, sendo que alguns valores podem não ser realizados economicamente. Além disso, o próprio Capital Social e as Reservas de Lucro podem ser vistos como uma figura jurídica, pois representam valores que os sócios renunciaram e investiram na sociedade (MARTINS et al.; 2013, p. 412). Assim, considerando que alguns valores dependem de realização futura, pode-se explicar a irrelevância do patrimônio líquido na estimação da Equação 1.

A Equação 2 permite analisar a relevância da informação contábil, em especial o efeito do dividendo adicional proposto. A especificação indicada pelo teste de Hausman também foram efeitos fixos. O teste de Newey West foi aplicado para corrigir os problemas de heterocedasticidade e autocorrelação dos resíduos. Embora haja uma forte relação entre lucro líquido e dividendo adicional proposto, conforme relatado na seção anterior, não foi identificado problema de multicolinearidade, pois o variance inflation factor (VIF) médio foi de 1,38 apenas. As variáveis $D A P$ e $L L$ não foram significantes estatisticamente, coerente com Al-Hares, AbuGhazaleh e Haddad (2012); eles não identificaram relevância da informação contábil quando lucro e dividendo são analisados em conjunto. Contudo, o dividendo torna-se relevante quando analisado sem a presença do lucro. Porém, em testes adicionais não reportados, observa-se que ambas se tornaram significantes estatisticamente quando separadas, provavelmente em função da forte correlação entre elas. Uma das consequências é que as variáveis $L L$ e $D A P$ explicam uma porção em comum do preço das ações, e, quando presentes na mesma regressão, podem resultar em aumento do erro padrão, e coeficientes estimados com baixa precisão (GUJARATI, 2000). No que diz respeito a $P L-D A P$, essa variável apresentou um resultado fraco, coerente com a Equação 1. Portanto, com base nesses resultados, constata-se que a Equação 2 apresenta um resultado não favorável à aceitação da hipótese de pesquisa deste estudo, inferindo que os dividendos adicionais propostos não são relevantes para o mercado de capitais.

Finalmente, as variáveis $L L, P L$ e $D A P$ foram estimadas isoladamente nas Equações 3, 4 e 5, respectivamente - vide Quadro 4. As três variáveis foram significantes estatisticamente, implicando informação relevante para o mercado de capitais, ao contrário da Equação 2. Ademais, ao comparar a magnitude dos coeficientes nota-se que a variável $D A P$ possui um efeito maior no preço das ações. Esse resultado confirma a hipótese de pesquisa de que o dividendo adicional proposto é relevante para o mercado de capitais.

Essa evidência é favorável à hipótese de sinalização investigada por Pettit (1972) e Miller e Rock (1985), pois os dividendos, representados pelo DAP, emitem um sinal de informação para o mercado, indicando oportunidades de investimento e crescimento. Assim, a divulgação do DAP pode despertar o interesse de investidores, explicando uma relação positiva com o preço das ações, de acordo com a Equação 5. Esse resultado também está em consonância com Lintner (1956), pois os dividendos são relevantes para os acionistas.

Complementarmente, apesar de não possuir uma característica de obrigação presente na data do balanço, de acordo com o ICPC 08 (R1), a informação sobre o Dividendo Adicional Proposto é relevante para o mercado de capitais, o que caracteriza a principal contribuição deste trabalho, isto é, mostra-se que uma informação associada a não obrigatoriedade de desembolso de fluxo de caixa pode ser extremamente útil no mercado de capitais, que, normalmente, reflete decisões de investidores buscando retorno de investimento. Além disso, os achados encontram-se em linha com Rees (1997), Brief e Zarowin (1999), Procianoy e Verdi (2003), Freire e Lima (2003), Kuronuma, Lucchesi e Famá (2004), Novis 
Neto e Saito (2003), Loss e Sarlo Neto (2003), Silva e Fávero (2007), Al-Hares, AbuGhazaleh e Haddad (2012), Brugni et al. (2012), Melo e Fonseca (2015) e Omokhudu e Ibadin (2015), os quais identificaram alguma relação entre a distribuição de dividendos e o comportamento dos investidores, representado pelo mercado de ações.

Com base nesses resultados, pode-se auferir que a divulgação do dividendo adicional proposto nas demonstrações contábeis é relevante para os investidores, revelando que essa informação pode implicar consequências econômicas para o mercado de capitais, visto que as empresas que registraram o DAP tiveram um efeito positivo no valor de mercado. Com isso, a existência de conteúdo informacional do DAP pode ser útil para muitos usuários da informação, por exemplo, os analistas de mercado que contribuem para reduzir a assimetria informacional entre os agentes. Com base nessas evidências, os analistas podem avaliar mais adequadamente os riscos e apresentar estimativas mais precisas. Consequentemente, a qualidade das previsões contábeis pode influenciar outros usuários da informação, como investidores ou acionistas, que, por sua vez, tomam decisões de compra, venda ou manutenção de investimentos em ações.

Outro grupo de possíveis interessados são os acionistas, que estão preocupados em avaliar a capacidade de distribuição de dividendos, além do potencial de valorização das ações das companhias. Os acionistas que recorrem à análise fundamentalista para avaliar a saúde financeira das empresas podem, de alguma maneira, fazer uso dessa informação, dada a relação positiva encontrada entre dividendo adicional e preço das ações.

\subsection{Análise de Robustez}

Em função do resultado divergente entre as Equações 2 e 5, alguns testes adicionais foram aplicados para identificar a especificação mais adequada. Para isso, os possíveis problemas decorrentes do uso de efeitos fixos propostos por Gujarati (2000) foram consultados. Entre eles, o autor comenta que, quando há muitas variáveis no modelo, "sempre há possibilidade de multicolinearidade, que pode dificultar uma estimação exata de um ou mais parâmetros". Posto isso, considerando a alta correlação entre as variáveis $L L$ e $D A P$ identificada na seção 4.1, decidiu-se excluir a variável $L L$. Com isso, os resultados das Equações 2 e 5 tornam-se coerentes, conforme Quadro 5.

Quadro 5 - Estimativas da Equação 2, após eliminar LL, e Equação 5

\begin{tabular}{|l|c|c|}
\hline & Equação 2 & Equação 5 \\
\hline PL-DPA & $223,87^{* *}$ & $833,76^{* *}$ \\
\hline$D P A$ & $830,01^{*}$ & \\
\hline$T A M$ & $-0,45^{*}$ & \\
\hline$C R E S C$ & $0,30 *$ & 210 \\
\hline ENDIV & 0,35 & $5,06 * *$ \\
\hline DIVOBRIG & $-0,12$ & Efeitos fixos \\
\hline$N$ & 189 & \\
\hline$F$ & $11,60 *$ & \\
\hline Especificação & Efeitos Fixos & \\
*significante a 1\%; **significante a 5\%;**significante a $10 \%$. \\
Fonte: Dados da pesquisa.
\end{tabular}


A variável $D A P$ é significante estatisticamente nas duas Equações, indicando que o Dividendo Adicional Proposto é relevante para o mercado de capitais, de acordo com a hipótese de pesquisa. Portanto, é possível afirmar que o anúncio de DAP pode influenciar positivamente o valor de mercado das empresas analisadas, o que possibilita ser visto como uma reação positiva dos investidores.

\section{Considerações Finais}

O estudo a respeito do papel da Contabilidade como fonte de informações para o mercado de capitais cresceu nos últimos tempos, principalmente com o desenvolvimento da escola positivista, sendo o trabalho de Lopes (2001) um dos precursores dessa escola no Brasil. Nesse sentido, o papel dos mercados de capitais para o desenvolvimento econômico aumenta o prestígio de estudos sobre a compreensão do papel da informação contábil.

A Interpretação Técnica ICPC 08 (R1) - Contabilização da Proposta de Pagamento de Dividendos - foi aprovada pela CVM, em 2009, e surgiu no contexto do processo de convergência contábil às normas internacionais do Internacional Financial Reporting Standards - IFRS, promovido pela Lei n. 11.638 de 2007. O ano de 2010 foi o primeiro em que as empresas foram obrigadas a adotar de forma completa as IFRS em suas demonstrações contábeis, sendo esta a base para a escolha do referido período.

Este trabalho teve como objetivo analisar o impacto do Dividendo Adicional Proposto (DAP), divulgado nas demonstrações contábeis de 2010 a 2012, no mercado de capitais. Mais especificamente investigou-se o efeito que o DAP exerce no preço das ações. O método baseia-se em Collins, Maydew e Weiss (1997), fundamentado pelo modelo de Ohlson (1995), o qual relaciona o valor da empresa com informações advindas da contabilidade.

Com base nos testes realizados, contatou-se que a divulgação da informação da conta dividendo adicional proposto, pelas empresas de capital aberto, é value relevant para o mercado de capitais no período analisado. Pela análise feita, pode-se auferir que a variável $D A P$ exerce maior influência sobre o preço das ações do que as variáveis $L L$ e PL-DAP, segundo a magnitude dos coeficientes apresentados no Quadro 4. Pôde-se, dessa forma, aceitar a hipótese de pesquisa de que o dividendo adicional proposto é relevante para o mercado de capitais. As Equações 3, 4 e 5 foram realizadas a fim de testar a significância estatística de lucro, patrimônio líquido e dividendo adicional proposto, as quais confirmaram as evidências empíricas anteriores.

Os achados indicam que a divulgação do Dividendo Adicional Proposto, nas demonstrações contábeis, é relevante para os investidores, confirmando a hipótese de sinalização, estudada por Pettit (1972) e Miller e Rock (1985), na qual os dividendos são um dos sinalizadores de informações emitidos pelas empresas. Um aumento na distribuição dos dividendos pode indicar, para os investidores, um sinal positivo de que os lucros maiores serão realizados no futuro, enquanto que a diminuição dos dividendos pode mostrar incertezas sobre o futuro da empresa. Essa informação pode implicar consequências econômicas favoráveis no mercado de capitais, já que as empresas que distribuem dividendo adicional proposto têm um aumento no valor de mercado.

Ademais, embora o dividendo adicional proposto não represente um passivo da empresa na data de sua divulgação, este estudo revela que o mercado usa essa informação para fins de decisão, coerente com diversos estudos que apontam para uma associação entre

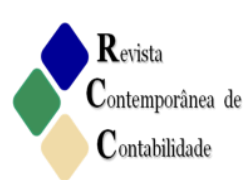


distribuição de dividendo e mercado de ações, entre eles: Rees (1997), Brief e Zarowin (1999), Procianoy e Verdi (2003), Freire e Lima (2003), Kuronuma, Lucchesi e Famá (2004), Novis Neto e Saito (2003), Loss e Sarlo Neto (2003), Silva e Fávero (2007), Al-Hares, AbuGhazaleh e Haddad (2012), Brugni et al. (2012), Melo e Fonseca (2015) e Omokhudu e Ibadin (2015). Esse resultado ainda pode ser de interesse de vários usuários da informação, por exemplo, analistas de mercado, investidores, e acionistas, os quais podem usar o dividendo adicional proposto em seus modelos de previsão ou avaliação, visto que a informação é relevante para o mercado de capitais.

Algumas limitações devem ser consideradas para esta pesquisa. Os resultados e as conclusões estão restritos à amostra, às variáveis utilizadas, ao período analisado e à metodologia empregada. Para o desenvolvimento de novas pesquisas, sugere-se a utilização de outros métodos como o estudo de evento.

\section{Referências}

AL-HARES, O. M.; ABUGHAZALEH, N. M; HADDAD, A. E. Value relevance of earnings, book value and dividends in an emerging capital market: Kuwait evidence. Global Finance Journal, v. 23 p. 221-234, 2012.

ALLEN, F.; BERNARDO, A. E.; WELCH I. A theory of dividends based on tax clienteles. The Journal of Finance, v. 55, n. 6, p. 2499-2536, 2000.

ALMEIDA, J. E. F. Qualidade da informação contábil em ambientes competitivos. São Paulo, 2010. Tese (Doutorado em Controladoria e Contabilidade) - Programa de PósGraduação em Ciências Contábeis, Departamento de Contabilidade e Atuária, Faculdade de Economia, Administração e Contabilidade, Universidade de São Paulo.

AMBROZINI, M. A. Política de dividendos no Brasil: um modelo de apoio à decisão. 2011. Tese de (Doutorado em Administração de Organizações) - Faculdade de Economia, Administração e Contabilidade, Universidade de São Paulo, Ribeirão Preto, 2011.

ASSAF NETO, A.; LIMA, F. G.; AMBROZINI, M. A. Dividendos: teoria e prática. Inside Books: Ribeirão Preto, 2007.

BALL, R.; BROWN, P. An empirical evaluation of accounting numbers. Journal of Accounting Research, v. 7, n. 2, p. 159-177, 1968.

BARTH, M. E.; BEAVER, W. H.; LANDSMAN, W. R. The relevance of the value relevance literature for financial accounting standard setting: another view. Journal of Accounting and Economics, v. 31, p. 77-104, 2001.

BEAVER, W. B. The information content of annual earnings announcements. Journal of Accounting Research, v. 6, p. 67-92, 1968. 
BERNARDO, H. P. Avaliação Empírica do efeito dos anúncios trimestrais do resultado sobre o valor das ações no mercado brasileiro de capitais - um estudo de evento. 2001. Dissertação (Mestrado em Controladoria e Contabilidade) - Faculdade de Economia, Administração e Contabilidade, Universidade de São Paulo, São Paulo, 2001.

BOLSA DE VALORES, MERCADORIAS E FUTUROS DE SÃO PAULO - BM\&F BOVESPA. Disponível em <http://www.bmfbovespa.com.br>. Acesso em: 10 de maio de 2015 .

BRASIL. Lei $\mathrm{n}^{\circ} 10.303$, de 31 de outubro de 2001. Altera e acrescenta dispositivos na Lei $\mathrm{n}^{\circ}$ 6.404, de 15 de dezembro de 1976, que dispõe sobre as Sociedades por Ações, e na Lei $\mathrm{n}^{\circ}$ 6.385, de 7 de dezembro de 1976, que dispõe sobre o mercado de valores mobiliários e cria a Comissão de Valores mobiliários. Diário Oficial da União, Brasília, DF, 31 out. 2001.

BRASIL. Lei n ${ }^{\circ}$ 6.404, de 15 de dezembro de 1976. Dispõe sobre as Sociedades por Ações. Diário Oficial da União, Brasília, DF, 15 dez. 1976.

BRASIL. Deliberação da Comissão de Valores Mobiliários n. 601, de 7 de outubro de 2009. Aprova a Interpretação Técnica ICPC 08 do Comitê de Pronunciamentos Contábeis, que trata da contabilização da proposta de pagamento de dividendos. Diário Oficial da União, Brasília, DF, 7 out. 2009.

BRIEF, R. P.; ZAROWIN, P. The value relevance of dividends, book value and earnings. New York University, Stern School of Business, Accounting. Working Paper, p. 99-103, 1999.

BRIGHAM, E. F.; GAPENSKI, L. C.; EHRHARDT, M. C. Administração Financeira: teoria e prática. Tradução Alexandre Loureiro Guimarães Alcântara e José Nicolas Albuja Salazar. São Paulo: Atlas, 2001.

BROWN, S.; LO, K.; LYS, T. Use of R2 in accounting research: measuring changes in value relevance over the last four decades. Journal of Accounting and Economics, v. 28, p. 83$115,1999$.

BRUGNI, T. V.; SARLO NETO, A.; BASTIANELLO, R. F.; PARIS, P. K. S. Influência de dividendos sobre a informatividade dos lucros: evidências empíricas na BMFBOVESPA.

Revista Universo Contábil, v. 8, p. 82-99, 2012.

BUENO, A. F. Análise empírica do dividend yield das ações brasileiras. São Paulo, 2000. Dissertação (Mestrado em Contabilidade e Controladoria) - Programa de Pós-Graduação em Ciências Contábeis, Departamento de Contabilidade e Atuária, Faculdade de Economia, Administração e Contabilidade, Universidade de São Paulo, 2000.

CAGNIN, R. F.; PRATES, D. M.; FREITAS, M. C. P.; NOVAIS, L. F. A gestão macroeconômica do governo Dilma (2011 e 2012). Novos Estudos - CEBRAP, n. 97, p. 169185,2013 
CASTRO, R. D.; MARQUES, V. A. Relevância da informação contábil para o mercado de capitais: evidências no mercado brasileiro. Enfoque, v. 32, p. 109-124, 2013.

COLLINS, D. W.; MAYDEW, E. L.; WEISS, I. S. Changes in the value-relevance of earnings and book values over the past forty years. Journal of Accounting and Economics, v. 24, n. 1, p. 39-67, 1997.

COMITÊ DE PRONUNCIAMENTOS CONTÁBEIS - CPC. Interpretação Técnica ICPC 08 (R1) - Contabilização da Proposta de Pagamento de Dividendos. Disponível em: <www.cpc.org.br>. Acesso: 3 nov. 2012.

DIEHL, C. A.; MACAGNAN, C. B.; ZANINI, F. A. M.; WICKBOLDT, L. A. Metodologias em Artigos de Finanças sobre Dividendos nos Periódicos Brasileiros Qualis/Capes a partir de B2. Revista pensamento contemporâneo em administração (UFF), v. 07, p. 23-43, 2010.

FAMA, E. F. Efficient capital markets: a review of theory and empirical work. The Journal of Finance. New York: The American Finance Association, v. 25, n. 1, p. 383-417, 1970.

FIGUEIREDO, A. C. O Conteúdo Informativo de Dividendos: Evidências no Brasil. In: Encontro Brasileiro de Finanças, 2, 2002, Rio de Janeiro - RJ. Anais..., 2002, Rio de Janeiro: SBFIN, 2002.

FRANCIS J.; SCHIPPER K. Have financial statements lost their relevance? Journal of Accounting Research, v. 37, n. 2, p. 319-352, 1999.

FREIRE, H. V. L.; LIMA, I. S. O comportamento dos dividendos versus lucros anormais. In: ENCONTRO NACIONAL DOS PROGRAMAS DE PÓS-GRADUAÇÃO EM ADMINSTRAÇÃO, 27, 2003, São Paulo-SP. Anais..., São Paulo: ANPAD, 2003.

FREIRE, H. V. L.; ZATTA, F. N.; DALMACIO, F. Z.; LOUZADA, L. C.; NOSSA, V. Dividendos e lucros anormais: um estudo nas empresas listadas na Bovespa. Revista Contabilidade \& Finanças, v. 3, p. 33-59, 2005.

GONZÁLEZ, P. As mudanças nas políticas de dividendos e o mercado financeiro. São Paulo: Caderno de Estudos, FIPECAFI, v. 10, n. 19, p. 70-81, set./dez. 1998.

GORDON, M. J. Optimal investment and financing policy. The Journal of Finance, v. 18, n. 2, p. 264-272, 1963.

GRÔPPO, G. S. Relação Dinâmica entre Ibovespa e Variáveis de Política Monetária. Revista de Administração Eletrônica, v. 46, edição especial, 2006.

GUJARATI, D. N. Econometria Básica. 3. ed. São Paulo: Makron Books, 2000. 
HOULTHAUSEN, R. W.; WATTS, R. L. The relevance of the value-relevance literature for financial accounting standard setting. Journal of Accounting and Economics, v. 31, n. 1-3, p. 3-75, 2001.

KOTHARI, S.; ZIMMERMAN, J. Price and Return Model. Journal of Accounting and Economics, v. 20, n. 2, p. 155-192, 1995.

KURONUMA, A. M.; LUCCHESI, E. P.; FAMÁ, R. Retornos anormais acumulados das ações no período pós-pagamento de dividendos: um estudo empírico no mercado brasileiro. In: CONGRESSO USP DE CONTROLADORIA E CONTABILIDADE, 4, 2004, São Paulo. Anais..., São Paulo, 2004. CD-ROW.

LIMA, J. B. N. A Relevância da Informação Contábil e o Processo de Convergência Para as Normas IFRS no Brasil. São Paulo, 2011. Tese (Doutorado em Controladoria e Contabilidade) - Programa de Pós-Graduação em Ciências Contábeis, Departamento de Contabilidade e Atuária, Faculdade de Economia, Administração e Contabilidade, Universidade de São Paulo, SP, Brasil, 2011.

LINTNER, J. Distribution of incomes of corporations among dividends, retained earnings, and taxes. The American Economic Review, v. 46, n. 2, p. 97-113, 1956.

LINTNER, J. Dividends, earnings, leverage, stock prices and the supply of capital to corporations. The Review Economics and Statistics. v. 44, n. 3, p. 243-269, 1962.

LOPES, A. B. A relevância da informação contábil para o mercado de capitais: o modelo de Ohlson aplicado à Bovespa. 2001. Tese (Doutorado em Controladoria e Contabilidade) Faculdade de Economia, Administração e Contabilidade, Universidade de São Paulo, São Paulo, 2001.

LOPES, A. B. A Informação Contábil e o Mercado de Capitais. São Paulo: Pioneira Thomson Learning, 2002.

LOPES, A. B.; MARTINS, E. Teoria da contabilidade: uma nova abordagem. São Paulo: Atlas, 2005.

LORIATO, A. G.; GOMES, L. L. Volumes anormais de negócios no mercado brasileiro de ações em função dos anúncios contábeis anuais. In: CONGRESSO USP DE

CONTROLADORIA E CONTABILIDADE, 6, 2006, São Paulo. Anais..., São Paulo, 2006.

LOSS, L.; SARLO NETO, A. Política de dividendos, na prática, é importante? Revista de Contabilidade e Finanças, São Paulo. Edição comemorativa, v. 14 p. 39-53, 2003.

MANTOVANI, D. M. N.; VIANA, A. B. N. Análise de regressão usando o SPSS. Ribeirão Preto, NPT/Educacional, FEARP/USP, 2011. [28] p. Tutorial utilizado em disciplina de Estatística Aplicada à Administração. 
MARTINS, A. I.; FAMÁ, R. O que revelam os estudos realizados no Brasil sobre política de dividendos? Revista de Administração Eletrônica, v. 52, p. 24-39, 2012.

MARTINS, E.; GELBCKE, E. R.; SANTOS, A.; IUDÍCIBUS, S. Manual de Contabilidade Societária. 2. ed. São Paulo: Atlas, 2013.

MARTINS, G. A; THEÓPHILO, C. R. Metodologia da investigação científica para ciências sociais aplicadas. 2. ed. São Paulo: Atlas, 2009.

MELO, F. J.; FONSECA, M. W. Política de dividendos no Brasil: uma análise na reação do mercado a anúncios de distribuição de dividendos. Revista Contemporânea de

Contabilidade, v. 12, n. 27, p. 137-164, 2015.

MILLER, M. H.; MODIGLIANI, F. Dividend policy, growth, and the valuation of shares.

The Journal of Finance, v. 34, n. 4, p. 411- 434, 1961.

MILLER, M. H.; ROCK, K. Dividend policy under asymmetric information. The Journal of Finance, v. 40, n. 4, p. 1031-1051, 1985.

MOREIRA, L. F. Multicolinearidade em análise de regressão. In: ENCONTRO REGIONAL DE MATEMÁTICA APLICADA E COMPUTACIONAL, 12, 2008, Foz do Iguaçu, Anais..., Foz do Iguaçu, 2008.

NISSIM, D.; ZIV, A. Dividend changes and future profitability. Journal of Finance, v. 56, n. 6, p. 2111-2133, 2001.

NOVIS NETO, J. A.; SAITO, R. Pagamento de dividendos e persistência de retornos anormais das ações: evidência do mercado brasileiro. Revista de Administração da USP. São Paulo, v. 38, n. 2, p. 135-143, 2003.

NUNES, M. S.; COSTA JUNIOR, N. C. A.; MEURER, R. A Relação entre o Mercado de Ações e as Variáveis Macroeconômicas: Uma Análise Econométrica para o Brasil. Revista Brasileira de Economia, v. 59, n. 4, out./dez. 2005.

OHLSON, J. A. Earnings, book values and dividends in equity valuation. Contemporary Accounting Research, v. 11, n. 2, p. 661-687, 1995.

OMOKHUDU, O. O.; IBADIN, P. O. The Value Relevance of Accounting Information: Evidence from Nigeria. Accounting and Finance Research, v. 4, n. 3, p. 20-30, 2015.

PETTIT, R. Richardson. Dividend announcements, security performance, and capital market efficiency. Journal of Finance, v. 27, n. 5, p. 993-1007, 1972.

PROCIANOY, J. L.; VERDI, R. O efeito clientela no mercado brasileiro: será que os investidores são irracionais? Revista Brasileira de Finanças, v. 1, n. 2, p. 217-242, 2003. 
QUEIROZ, P. W. V.; CRUZ, A. C. Efeitos da Produtividade, Demanda e Distribuição de Renda no Crescimento Brasileiro. In: ENCONTRO NACIONAL DE ECONOMIA, 42 2014, Natal (RN), Anais... Natal: ANPEC, 2014. Disponível em: 〈www.anpec.org.br〉.

REES, W. The Impact of Dividends, Debt and Investment on Valuation Models. Journal of Business Finance and Accounting, v. 24, p. 1111-1140, 1997.

SANTANA, L. Relação entre dividend yield e retorno das ações abordando aspectos determinantes da política de dividendos: um estudo empírico em empresas com ações negociadas na BOVESPA. Dissertação (Mestrado em Ciências Contábeis) - Fundação Instituto Capixaba de Pesquisas em Contabilidade, Economia e Finanças, Vitória, 2006.

SANTOS, M. A. C.; CAVALCANTE, P. R. N. O Efeito da Adoção dos IFRS sobre a Relevância Informacional do Lucro Contábil no Brasil. Revista de Contabilidade e Finanças, v. 25, n. 6, p. 228-241, 2014.

SARLO NETO, A.; LOPES, A. B.; COSTA, F. M. O conteúdo informativo da contabilidade: um estudo sobre o impacto da divulgação das informações contábeis no mercado brasileiro abordando o efeito liquidez. In: CONGRESSO BRASILEIRO DE FINANÇAS, 6 2006, Vitória (ES), Anais... Vitória: SBFin, 2006.

SARTORELLI, I. C. Stock Options: um ensaio teórico. 2010. Dissertação (Mestrado em Ciências Contábeis) - Programa de Pós-Graduação em Ciências Contábeis, Departamento de Contabilidade e Atuária, Faculdade de Economia, Administração e Contabilidade, Universidade de São Paulo, São Paulo, SP, Brasil, 2010.

SCARPIN, J. E.; PINTO, J.; BOFF, M. L. A relevância da informação contábil e o mercado de capitais: uma análise empírica das empresas listadas no índice Brasil. In: CONGRESSO USP DE CONTROLADORIA E CONTABILIDADE, 7, 2007, São Paulo. Anais..., São Paulo, 2007.

SCHIEHLL, E. O efeito da divulgação das demonstrações financeiras no mercado de capitais brasileiro: um estudo sobre a variação no preço das ações. 1996. Dissertação (Mestrado em Administração) - Faculdade de Ciências Econômicas, Universidade Federal do Rio Grande do Sul, Porto Alegre: UFRGS, 1996.

SILVA, R. L. M. Adoção completa das IFRS no Brasil: qualidade das demonstrações contábeis e o custo de capital próprio. 2013. Tese (Doutorado em Ciências Contábeis), Programa de Pós-Graduação em Ciências Contábeis, Departamento de Contabilidade e Atuária, Faculdade de Economia, Administração e Contabilidade, Universidade de São Paulo, São Paulo, SP, Brasil, 2013.

SILVA, R. F.; FAVERO, L. P. L. O impacto da divulgação das informações contábeis na variação do preço de ativos no mercado financeiro. In: CONGRESSO USP DE INICIAÇÃO CIENTÍfICA, 4, 2007, São Paulo. Anais..., São Paulo, 2007. 
SILVA, F. M.; CORONEL, D. A. Análise da Causalidade e Cointegração entre Variáveis Macroeconômicas e o Ibovespa. Revista de Administração FACES Journal, v. 2, n. 3, p. 31-52, jul./set. 2012.

SILVA, R. L. M.; NARDI, P. C. C. N. Demonstrações Contábeis no Brasil após Adoção do CPC 13: Reação do Mercado de Ações. Advances in Scientific and Applied Accounting, v. 7, n. 3, p. 362-385, set./dez. 2014.

SOBRINHO, W. B. R.; RODRIGUES, H. S. Dividendos e accruals discricionários: um estudo sobre a relação entre a política de distribuição de dividendos e a qualidade dos lucros. Revista Contemporânea de Contabilidade, v. 11, n. 24, p. 03-24, 2014.

VANCIN, D. F.; PROCIANOY, J. L. Índices contábeis e a decisão do pagamento de dividendos. Revista Contemporânea de Contabilidade, v. 13, n. 28, p. 57-80, 2016.

YAMAMOTO, M. M.; SALOTTI, B. M. Informação Contábil: Estudos sobre a sua Divulgação no Mercado de Capitais. São Paulo: Atlas, 2006.

WATTS, R. L.; ZIMMERMAN, J. L. Positive Accounting Theory. $1^{\text {st }}$ ed. New Jersey: Prentice-Hall, 1986. 